\title{
Evaluating the Effectiveness of Training Program Developed for Teachers Working with Dyslexic Students on their Competencies
}

\author{
Hasan KIZILKAYA ${ }^{1}$ \\ Hakan SARI ${ }^{2}$
}

'Dr., Karamanoğlu Mehmetbey University, School of Foreign Languages, Karaman, Turkey. Email:hasankizilkaya35@gmail.com Tel: +905398488520

'Prof. Dr., Necmettin Erbakan University, Special Education Department, Konya, Turkey.

Email:hakansari@gmail.com Tel:+905053467401

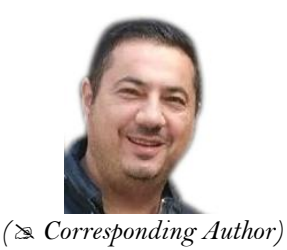

\begin{abstract}
In Turkey, the number of studies determining the competence level of classroom teachers working with dyslexic students is limited. It is thought that a dyslexia training program, which will be developed based on teacher needs, will meet the training needs of teachers. In this study expletory sequential mixed method was adopted and, qualitative research method was used in the first stage and quantitative research method in the second stage. In the first stage, the teacher training program was developed in the light of the data obtained by semi-structured interview technique. Pre-test post-test control group experimental design was preferred in the process of evaluating the effectiveness of the program. The study group consists of 46 teachers working in primary schools of Karaman province. The independent samples t-test analysis between the two groups and the dependent group t-test analysis between the pre-test post-test scores revealed a significant difference between the means of the groups. As a result, teachers who consider themselves competent and receive the necessary training will both support their students with dyslexia more comprehensively and display a more positive attitude.
\end{abstract}

Keywords: Dyslexia, Teacher training program, Teacher competencies, Special education, Reading difficulties.

Citation | Hasan KIZILKAYA; Hakan SARI (2021). Evaluating the Effectiveness of Training Program Developed for Teachers Working with Dyslexic Students on their Competencies. Asian Journal of Education and Training, 7(2): 126-135.

History:

Received: 5 March 2021

Revised: 8 April 2021

Accepted: 12 May 2021

Published: 3 June 2021

Licensed: This work is licensed under a Creative Commons

Attribution 3.0 License (c)) E

Publisher: Asian Online Journal Publishing Group
Acknowledgement: Both authors contributed to the conception and design of the study. This paper is produced and translated from PhD thesis entitled "Disleksili Öğrencilerle Çalışan Öğretmenler için Geliştirilen Eğitim Programının Öğretmen Yeterliklerine Etkisinin İncelenmesi".

Funding: This study received no specific financial support.

Competing Interests: The authors declare that they have no conflict of interests.

Transparency: The authors confirm that the manuscript is an honest, accurate, and transparent account of the study was reported; that no vital features of the study have been omitted; and that any discrepancies from the study as planned have been explained.

Ethical: This study follows all ethical practices during writing.

\section{Contents}

1. Introduction

3. Results

References.. 


\section{Contribution of this paper to the literature}

It is thought that this study with dyslexia training program, which developed based on teacher needs, will meet the training needs of teachers regarding reading difficulties. Meeting the educational needs of teachers will not only increase teacher competencies, but also enable students with dyslexia who continue inclusive education to have a dyslexia-friendly classroom environment.

\section{Introduction}

The education of children with dyslexia should not be carried out only with normal plans and programs. While the child continues his education, he/she should also receive training in groups or individually. The strengths and weaknesses of the child should be determined and an education program should be arranged accordingly. The training should include the development of visual, auditory, tactile, perception, attention, memory, sequential ability, motor skills, as well as the development of speaking, listening, reading-writing skills, and supporting the development of concepts and thinking. Training of learning difficulties should be provided by an expert educator trained in this field. As a result of the evaluations to be made, the teacher will identify the child's missing skills and make a plan in that regard. An emotionally safe and stimulating environment for his / her skills and development should be designed in the classroom. Practices that provide a sense of success about homework should be employed and homework assignments should be checked. Another issue that should be considered is that the homework given to the child should be organized step by step, from easy to difficult. The most appropriate program that can be given to the child should be arranged by providing teacher-expert and parent collaboration (MEB, 2014; Reid, 2009).

Although dyslexia occurs with neurobiological differences related to reading and language problems, it is mainly treated with effective teaching. Especially early diagnosed and effective classroom education can prevent or at least effectively address and limit reading and writing problems. It is predicted that even when early diagnosis is late, the most serious reading obstacles can be improved in primary school with intensive teaching and students can progress towards academic success. When competent intervention is made to individuals with dyslexia, the impact of the disorder can be reduced and can help the student overcome and manage the most challenging difficulties (Hultquist, 2006). It can be said that the most important factor determining the course of dyslexic student behavior and educational progress is the attitude of the teacher. Similarly, international studies show that a teacher's capacity to cope with different learning difficulties is influenced by his knowledge of these difficulties (Gwernan-Jones \& Burden, 2010). Systematic research is required to identify and improve teachers' knowledge and attitudes towards meeting the needs of students affected by dyslexia. Teaching reading and writing to students with language problems requires effective knowledge and skills. Undergraduate and professional development practices approved by many governments are insufficient to prepare and support teachers and specialists. The majority of teachers do not seem to have sufficient knowledge to prevent reading problems, recognize early risk symptoms, or successfully teach students with dyslexia and specific learning difficulties. It is noteworthy that there is a widespread absence of rich content training programs for empowering teachers and experts in dyslexia. When the teacher training undergraduate programs are examined, it is revealed that very few of them are compatible with current research on effective teaching for students at risk. In-service teacher training programs should be prepared in order to encourage effective teacher training and professional development covering these shortcomings.

Teacher training is not only important in all levels of general education, but also special education (Sari, 2007). Nowadays, the thought that each student can exhibit their own problem behaviors due to the different characteristics of each student has increased the importance given to the education of all students with special educational needs. The purpose of special education is defined as providing opportunities for students to reveal their potentials and use them at the highest level, to be self-sufficient, environmentally compatible, and productive individuals. The quality of special education services depends on the quality of teacher who will provide these services (Sari, 2004). Since the teaching profession has strategic importance compared to other professions in terms of the upbringing, development, and education of future adults, it is thought that this research will have strategic importance in terms of the teaching profession of the future. It is thought that by increasing the competence of classroom teachers in dyslexia, which is the most common learning difficulty, they can support their students with dyslexia more effectively.

Evaluating the effect of the training program developed for teachers on teacher competencies for eliminating reading difficulties in students with dyslexia is the subject of this study. With the increase of scientific studies in the field of special education, education studies for a wide variety of very special areas within a single disability area have started to gain weight rather than studies for the whole special education categories. These studies turn the special education categories into more detailed areas. Perhaps the most striking of these categories, dyslexia as a special education category is very frequently heard in recent years in Turkey as well as all over the world. For this reason, it should be aimed to reveal the diagnosis and individual characteristics of children with dyslexia very well before determining their needs. Educational activities for students diagnosed with dyslexia may require working in many different strategies and contents. For example, most children can make rapid progress when they receive one-on-one, intensive and continuous training. Some may require intensive one-to-one training in a group. All these features require teachers to have special competencies to work with students diagnosed with dyslexia.

The number of studies determining teachers' competence level working in the field of special education and efforts to increase this level is limited in Turkey. Besides, there are very few training studies among programs of in-service training and faculties for specific areas such as dyslexia. Although there is a course of teaching reading and writing in primary school teaching programs, there are not enough practices and contents to increase teacher competencies in eliminating reading difficulties. Classroom teachers cannot adequately support students with dyslexia in their classrooms due to their insufficiency in dyslexia, the most common learning difficulty. It is thought that a dyslexia training program, which will be developed based on teacher needs, will meet the training needs of teachers in this context. Meeting the educational needs of teachers will not only increase teacher 
competencies but also enable students with dyslexia who continue inclusive education to have a dyslexia-friendly classroom environment. Teachers' competencies will also be low in an area they consider themselves inadequate, but an effective training program will increase teachers' competencies. The teacher who feels self-sufficient will be more effective in providing an appropriate educational environment and activities to his students with dyslexia, and his attitudes towards his students with dyslexia will also improve positively.

This research aims to evaluate the effect of the education program developed for teachers on teacher competencies for eliminating reading difficulties in students with dyslexia. In this study, six sub-questions will be answered in light of the main aim of the research. These six sub-questions are listed below.

1) What are the teachers' views on the needs of the teacher education program to be developed in line with the teaching needs of students with dyslexia?

2) Is there a statistically significant difference between the pre-test scores of the experimental and the control group in the teacher education program developed to eliminate reading difficulties in students with dyslexia?

3) Is there a statistically significant difference between the pre-test post-test scores of the control group in the teacher education program developed to eliminate reading difficulty in students with dyslexia?

4) Is there a statistically significant difference between the post-test scores of the experimental group and the control group of the teacher education program developed to eliminate reading difficulties in students with dyslexia?

5) Is there a statistically significant difference between the pre-test post-test scores of the experimental group in the teacher education program?

6) Is there a statistically significant difference between the post-test and retention test scores of the teacher education program?

\section{Method}

Since both qualitative and quantitative methods were used together in the study, the research method was determined as the mixed research method. In this study, which was carried out in order to evaluate the effectiveness of the training program developed for teachers with students with dyslexia, a two-stage exploratory design among mixed methods was used as a research model. This method was preferred because both qualitative and quantitative data collection methods were used to realize the purpose of evaluating the effectiveness of the program developed based on needs analysis. The exploratory design model is a two-step approach and is called Sequential Exploratory Design (Creswell, 2007). This design starts with qualitative data to discover a phenomenon and then moves on to a second quantitative phase. Using this design, researchers develop a tool based on the results of the qualitative phase and make propositions for tests based on an emerging theory or outline. This situation links the first qualitative stage to the next quantitative component of the study. First, the subject is explored qualitatively and they develop themes from their qualitative data. They then develop a tool based on these results and then use this tool in the quantitative phase that takes the second phase of the study (Cohen, Manion, \& Morrison, 2017).

In the first stage of the study, one of the qualitative research methods, the interview technique was preferred. In order to determine the goal, achievement, and content of the training program to be developed, a needs analysis was conducted at the first stage of program development. Necessary data for needs analysis were obtained by interview method. Semi-structured interview technique has been adopted among the interview methods. Interviewing is often a qualitative research technique that involves asking open-ended questions to participants to gather emerging data on a topic. In most cases, the interviewer is a subject matter expert who tries to understand the opinions of the participants through a series of well-planned and executed questions. In the interview technique, the researcher has to interview a group of participants at some point in the research, where information can be obtained by meeting only a portion of their target audience and establishing a personal connection. Interviews provide researchers with a platform to guide their participants and obtain data in desired details. There are three basic types of interviews in qualitative research: structured, semi-structured, and unstructured (Hartas, $2010)$.

The quantitative research method was used in the second stage of this study, in which the mixed method was adopted. In the first stage, a dyslexia teacher training program was developed as a result of the analyzes performed in the light of the data obtained by semi-structured interview technique, one of the qualitative research methods. In the process of evaluating the effectiveness of the developed program, an experimental design with a pre-test posttest control group was preferred among quantitative research methods. Measurements were made on the sample before and after the program implementation. The sample was divided into two different groups, and only one group received implementation, but the measurement process was carried out to both groups before and after the implementation. Evaluation of intervention programs is at the center of educational research. It is important to collect data from several points over time for application evaluation, such as pre-testing, post-testing, and followup evaluations, to test the long-term strength of implementation effects. Generally, the pre-test post-test pattern (before and after the intervention) represents a method widely used in the field of educational practice (Gliner, Morgan, \& Harmon, 2003).

\subsection{Study Sample}

Primary school teachers constitute the universe of the study. 25 teachers working in primary schools of the central district of Karaman province were determined as samples for the qualitative phase of the study. 46 teachers working in primary schools of the central district of Karaman were determined as samples for the quantitative phase of the study. While 23 teachers were determined as the experimental group, 23 teachers were determined as the control group. Demographic information of the participants is presented in the table 1 below. 28 of the participants are women $(60.87 \%)$ and 18 of them are men $(39.13 \%)$. While creating the experimental and control groups, gender distribution was taken into consideration. 14 of 28 female teachers were in the experimental group and 14 were in the control group; Of the 18 male teachers, 9 were assigned to the experimental group and 9 to the control group. 
Table-1. Demographic Information of Participants.

\begin{tabular}{c|c|c|c|c}
\hline Gender & Experimental Group & Control Group & $\mathbf{N}$ & \% \\
\hline Male & 9 & 9 & 18 & 39.13 \\
\hline Female & 14 & 14 & 28 & 60.87 \\
\hline Total & 23 & 23 & 46 & 100 \\
\hline
\end{tabular}

\subsection{Data Collection Tools}

In this study, in which the mixed method was adopted, both qualitative and quantitative data collection tools were used in the data collection process. In the first stage of the study, data were collected from teachers by interview method in order to determine the training needs of teachers. At this stage, the data were collected using semi-structured interview technique, one of the qualitative research methods. In the second stage of the research, the training program developed in light of the data collected in the first stage was implemented. The achievement test developed to evaluate the effect of the program was used. At this stage, one of the quantitative research methods, pre-test post-test control group quasi-experimental design was adopted.

\subsubsection{Qualitative Data Collection Tool}

The semi-structured interview form, which is used as a qualitative data collection tool within the scope of the research, consists of two parts: the informative text and the interview part. In the information section, the participant was informed about the subject and importance of the research, and it was also stated that the participation was voluntary and the information of the participants would not be shared with third parties. In the interview form, questions were included to determine the training needs of the participants on dyslexia. Before the interview form was applied, it was presented for an expert opinion. The necessary changes were made to the interview form, taking into account the feedback from the expert opinion. Later, the semi-structured interview form was applied to five teachers as a pilot application. The interview form was finalized, taking into account the feedback of the teachers participating in the pilot application and the experiences of the researcher.

\subsubsection{Quantitative Data Collection Tool}

Dyslexia teacher education program achievement test was used as a quantitative data collection tool in the study. In the first stage of the achievement test development, question items and options were written based on expert opinions including the goals and achievements of the training program to be implemented. The questions were prepared with 5 options. The 60-question draft prepared was sent to 3 experts in the field of the achievement test and they were asked to evaluate. After expert opinions, 10 questions were removed from the test and a 50question test was made ready for pilot application. After the first pilot application, the final test consisting of 40 questions was applied to 8 teachers within the scope of the pilot application. One of the aims of this application is to determine whether there are unclear questions and/or unknown words in the test. Incomprehensible questions and unknown words may cause the test to go beyond its purpose. The second goal is to determine how many minutes the test can solve on average. Teachers participating in the pilot application answered the test in 32-36 minutes. The response time of the test was determined as 40 minutes.

In order to determine the reliability of the developed achievement test, item difficulty, and discrimination indices, a pilot study was conducted with a total of $168(\mathrm{n}=168)$ classroom teachers. The results resulting from the application are given in Tables 2 and 3 . When the data were examined, it was observed that the discrimination values of the items in the test were between .15 and .83 and 10 items with a value below .29 should be excluded from the test (Wendler \& Walker, 2011). Ten items that did not meet the minimum discrimination value were directly excluded from the test. Forty questions left in the final form of the achievement test developed.

Table-2. Item Difficulty and Item Discrimination Index.

\begin{tabular}{|c|c|c|c|c|c|}
\hline Item & $\mathbf{P}$ & D & Item & $\mathbf{P}$ & D \\
\hline 1 & 0.56 & 0.46 & 26 & 0.45 & 0.56 \\
\hline 2 & 0.43 & 0.48 & 27 & 0.55 & 0.73 \\
\hline 3 & 0.41 & 0.27 & 28 & 0.57 & 0.77 \\
\hline 4 & 0.57 & 0.81 & 29 & 0.54 & 0.75 \\
\hline 5 & 0.86 & 0.27 & 30 & 0.51 & 0.65 \\
\hline 6 & 0.58 & 0.67 & 31 & 0.53 & 0.73 \\
\hline 7 & 0.44 & 0.58 & 32 & 0.47 & 0.44 \\
\hline 8 & 0.50 & 0.67 & 33 & 0.70 & 0.23 \\
\hline 9 & 0.55 & 0.85 & 34 & 0.47 & 0.52 \\
\hline 10 & 0.43 & 0.65 & 35 & 0.52 & 0.46 \\
\hline 11 & 0.66 & 0.65 & 36 & 0.28 & 0.27 \\
\hline 12 & 0.39 & 0.27 & 37 & 0.65 & 0.54 \\
\hline 13 & 0.30 & 0.23 & 38 & 0.54 & 0.83 \\
\hline 14 & 0.54 & 0.79 & 39 & 0.30 & 0.23 \\
\hline 15 & 0.51 & 0.73 & 40 & 0.46 & 0.75 \\
\hline 16 & 0.46 & 0.67 & 41 & 0.45 & 0.56 \\
\hline 17 & 0.46 & 0.63 & 42 & 0.45 & 0.69 \\
\hline 18 & 0.48 & 0.63 & 43 & 0.44 & 0.46 \\
\hline 19 & 0.54 & 0.63 & 44 & 0.45 & 0.73 \\
\hline 20 & 0.54 & 0.25 & 45 & 0.46 & 0.58 \\
\hline 21 & 0.54 & 0.67 & 46 & 0.22 & 0.15 \\
\hline 22 & 0.51 & 0.65 & 47 & 0.45 & 0.60 \\
\hline 23 & 0.51 & 0.73 & 48 & 0.51 & 0.73 \\
\hline 24 & 0.49 & 0.60 & 49 & 0.33 & 0.21 \\
\hline 25 & 0.52 & 0.79 & 50 & 0.56 & 0.79 \\
\hline
\end{tabular}


KR-20 and KR-21 are reliability analysis calculations developed by Kuder Richardson and found a lot in test development guides. While the main difference between the two analyzes requires knowing the number of correct answers to each item in the KR-20 test, KR-21 can be made if the total number of items in the test, mean and standard deviation are known. Also, KR-21 assumes that all items in the test have equal discrimination values. Although it is more difficult to apply, KR-20 is the most appropriate method (Kubiszyn \& Borich, 2003). One of the methods of determining the test reliability is to calculate the internal consistency of the test. KR-20 analysis is a statistical process that gives the internal consistency coefficients of items with two results (especially multiplechoice or answer as agree-disagree) (Swerdlik, Edward, Sturman, \& Cohen, 2012). The analysis and reliability studies of the achievement test developed within the scope of the study were calculated with the KR-20 reliability coefficient. While the KR-20 value of the 50-item form of the test was .91, the KR-20 value of the final version, which was reduced to 40 items, was calculated as .95 . The results of the reliability analysis for the final achievement test consisting of 40 questions are given in Table 3.

\begin{tabular}{c|c|c|c|c|c}
\multicolumn{7}{c}{ Table-3. KR-20 reliability value of achievement test and test analysis. } \\
\hline $\mathbf{N}$ & Item & $\mathbf{\mathbf { x } ^ { - }}$ & $\mathbf{S S}$ & $\mathbf{P}$ & rKR20 \\
\hline $\mathbf{1 6 8}$ & 40 & 27.92 & 9.69 & 0.52 & 0.95 \\
\hline
\end{tabular}

\subsection{Data Collection}

The data collection process was carried out in two stages: collecting qualitative data and collecting quantitative data. In order to determine the educational needs of teachers with students with dyslexia, 25 teachers were interviewed within the scope of needs analysis. All interviews were conducted face to face. The interviews were conducted in the university where the researcher works and the schools where the teachers work. The place and time of the meeting were determined according to the demands of the participants. The interviews were held in January 2020. During the interviews, the necessary approvals and permissions of the participants were obtained and the interviews were recorded with the help of a tape recorder. The data obtained from the interviews were analyzed with the descriptive analysis technique and the program content was started to be formed according to the results of this analysis. Dyslexia teacher training program was developed after literature review, needs analysis, and expert opinion (Moeckli, 2011).

The quantitative data in the study were collected with the dyslexia teacher training program achievement test developed within the scope of the research. The achievement test was applied to the participant teachers in both control and experimental groups before the application of the training program. The applied achievement test results were transferred to the computer as a pre-test. After the application, the achievement test was applied to both groups as a post-test, and the data obtained were transferred to the computer environment for statistical analysis. Necessary research permissions were obtained before the achievement test and program implementation. Achievement test practices were applied under the supervision of the researcher. The participants were reminded that they should be sincere in their answers while solving the achievement test for data validity and reliability. Before the achievement test was applied as a pre-test and a post-test, the necessary item analyzes were made and detailed information regarding this was given under the relevant heading. The training program developed based on the needs analysis after the pre-test was applied to the experimental group. In the light of the data obtained within the scope of the need analysis, the dyslexia teacher training program consisting of 7 units and 14 sessions was implemented in a 7-week implementation process, two days a week and one session a day. After the application, the achievement test was applied again as a post-test.

\subsection{Data Analysis}

Data collected by different methods at different stages of the study were analyzed with different methods. In the first stage of the research, the data collected by semi-structured interview technique in qualitative research methods were analyzed with the descriptive analysis technique used in the analysis of qualitative data. In the second stage of the study, the data obtained by the experimental design method with pre-test post-test control group, one of the quantitative research methods, were analyzed by statistical analysis methods through SPSS computer software.

A combination of quantitative and qualitative analysis is required to understand that an intervention has a 'why' effect. When properly applied, descriptive analysis can help researchers understand a phenomenon of interest and use this information to prioritize possible causal mechanisms, formulate hypotheses and intervention strategies, diagnose problems, and identify new problems (Walliman, 2010). Interviews were conducted with the teachers who participated in the study in order to determine the goals, objectives, and content of the dyslexia teacher training program developed based on the need analysis. The data obtained from these interviews were first transformed into textual data and descriptive analysis was applied. Concepts and themes were determined for each interview and each question of each interview. The goals, achievements, and content of the program were shaped in line with the themes created.

The quantitative data obtained in the study were analyzed through SPSS, a statistical analysis program for social sciences. The achievement test results applied to the experimental and control groups as pretest and posttest were analyzed to determine the effectiveness of the program. First of all, the normality test was conducted to reveal whether the data were suitable for normal distribution. The best known of these tests are Chi-Square, KolmogorovSmirnov, Lilliefors, and Shapiro-Wilk normality tests. Among these tests, considering the sample size $(\mathrm{n}<50)$, Shapiro - Wilk and Kolmogorov-Smirnov normality tests were used.

Table-4. Experimental group normality test result.

\begin{tabular}{c|c|c|c|c|c|c}
\hline \multirow{2}{*}{ Group } & \multicolumn{3}{|c|}{ Kolmogorov-Smirnov } & \multicolumn{3}{c}{ Shapiro-Wilk } \\
\cline { 2 - 7 } & Statistic & Df & Sig. & Statistic & Df & Sig. \\
\hline Experimental & 0.101 & 23 & 0.200 & 0.975 & 23 & 0.803 \\
\hline Note: $\mathrm{p}<0.05$ &
\end{tabular}

Note: $\mathrm{p}<0.05$. 
In the light of the data obtained, the dependent sample t-test from the parametric tests and the independent sample t-test from the parametric tests were used to analyze the relationship of the groups with each other and within the group. The reason for using this test is that the t-test allows us to compare the mean values of the two data sets and determine whether they come from the same population (Brown \& Melamed, 2012).

\section{Results}

In this section, the findings regarding the research results are given in line with the sub-questions.

\subsection{Results Regarding the First Sub-Question}

In order to determine the content of the teacher education program developed to cope with reading difficulties, 25 teachers were interviewed using the semi-structured interview method within the scope of the need analysis. The data obtained from the interviews were analyzed with the descriptive analysis technique and an answer was sought for the question of what the teacher education program needs, which is the first sub-question of the study. Findings obtained within the scope of themes created as a result of descriptive analysis are given here.

All of the teachers interviewed within the scope of the need analysis (25: $100 \%)$ find themselves inadequate in overcoming reading difficulties. Teachers generally stated that they did not receive training on teaching methods and techniques they would use to cope with reading difficulties in undergraduate education and that they only heard some terms conceptually in in-service training. They interpreted this situation as the most important factor in seeing themselves as inadequate. They stated that they researched to improve themselves and be more useful to their students with reading difficulties, but these individual efforts were also ineffective. They also stated that the feeling of not being useful to the students who need them, and the inability they experience, creates a situation of stress and anxiety.

The majority of the teachers who participated in the interview (24: 96\%) stated that they needed training to overcome reading difficulties, while only one teacher $(4 \%)$ stated that he did not need the training to overcome reading difficulties based on dyslexia. They stated that the education teachers will receive on reading difficulties will be very beneficial and will both improve themselves and contribute greatly to the development of their students. Besides, they stated that they definitely wanted to participate in this training, and most of the classroom teachers needed such training because the most common learning disability in classrooms was reading difficulty. While explaining their opinions about the educational need, teachers also stated that they did not want abnormal children in their classrooms where they criticized them considering their past experiences. They also stated that the training they will receive should be given by an expert and should be practical. They stated that if they receive such an education, they can now help their students without sending them to guidance and research center because the students they refer to guidance and research center get results in the form of only mainstreaming students and they continue their education with the children themselves. They emphasized that the fact that they are classroom teachers and that they did not receive special education in the field of reading difficulties is not taken into consideration by the guidance and research center and they cannot receive the necessary support.

The subject titles and frequencies formed as a result of the analysis of the answers given to the question of what are your opinions about the subjects you need education for eliminating the reading difficulties of teachers as a classroom teacher are evaluated. Most of the teachers (18: 72\%) stated that they need education about basic concepts and terms. It is seen that the proficiency levels of teachers in terms of definitions and concepts related to dyslexia are quite low. In addition, the subject of basic concepts is followed by the low reading speed and reading comprehension with a rate of $68 \%$. It can be found that teachers should be trained to support students with reading difficulties in reading comprehension and low reading speed. The need for training in poor reading and skipping letters while reading was expressed by $15(60 \%)$ teachers. Most of the teachers stated that they encounter students with reading difficulties every semester and they mostly notice this situation during letter-sound teaching, so a student with reading difficulties is immediately noticed in the first semester of the first grade. They stated that one of the most common problems is that these students write the letters backward and they have great difficulty reading these letters. They emphasized that difficulties such as slow reading, incomprehension, word, syllable, and voice skipping are very common in these children.

\subsection{Results Regarding the Second Sub-Question}

Findings related to testing the significant difference between the pre-test scores of the experimental group and the control group of the teacher education program achievement test, which was developed to eliminate reading difficulties in students with dyslexia, are included under this heading. In order to make sure that the experimental and control groups show similar characteristics before the application and to better understand the effectiveness of the teacher education program in practice, the achievement test developed by the researcher was applied to the groups before the first application, and the findings and comments about it are given in this section.

\begin{tabular}{c|c|c|c|c|c}
\multicolumn{6}{c}{ Table-5. Findings regarding experimental group and control group pre-test scores. } \\
\hline Group & $\mathbf{N}$ & $\mathbf{S}-\mathbf{W}$ & $\mathbf{x}$ & $\mathbf{S S}$ & $\mathbf{p}$ \\
\hline Experimental & 23 & 0.803 & 35.54 & 10.36 & 0.879 \\
\hline Control & 23 & 0.147 & 35.97 & 8.78 & \\
\hline Note: $\mathrm{p}<0.05$.
\end{tabular}

According to the achievement test pre-test results, the average of the experimental group was 35.54 and the standard deviation was 10.36; the average of the control group is 35.97 and its standard deviation is 8.78 . The fact that the averages are close to each other shows that the levels of the two groups are close to each other. As it was seen that there was no significant difference between the results of the normality test in the achievement test results applied to the groups before the first application, it was accepted that the data showed a normal distribution, as a result, the significance of the difference between the group averages was tested through the independent group 
t-test from parametric tests. The $\mathrm{p}$-value $(\mathrm{p}=.879)$ obtained as a result of the independent group t-test analysis between the two groups reveals that there is no significant difference between the means of the groups.

According to the analysis results of the pre-test scores performed before the application, the reading difficulties and coping skills of the teachers in the experimental group and the control group are close to each other. However, it is possible to say that teachers' competence in coping with reading difficulties is low. As seen in Table 5, the average score in both groups is below 40 points. It was found that teacher competencies in dealing with dyslexia, the most common learning difficulty, were at a lower than they should be.

\subsection{Results Regarding the Third Sub-Question}

The findings related to the significant difference between the pre-test post-test scores of the control group of the teacher education program, which was developed to eliminate reading difficulties in students with dyslexia, are given under this title. The achievement test developed within the scope of the research was applied as a pre-test and a post-test to the control group, who continued traditional in-service training activities and did not receive the dyslexia teacher training program. While the training program was applied to the experimental group, the control group continued with traditional in-service training activities. After the program implementation, the pre-test and post-test results of the control group were compared in order to compare the post-test results of both the experimental group and the control group and to evaluate the effectiveness of the program in the group that was not applied.

\begin{tabular}{c|c|c|c|c|c|c}
\multicolumn{7}{c}{ Table-6. Findings regarding the control group pre-test post-test scores. } \\
\hline Test & $\mathbf{N}$ & $\mathbf{S}-\mathbf{W}$ & $\mathbf{x}$ & $\mathbf{S S}$ & $\mathbf{T}$ & $\mathbf{p}$ \\
\hline Pre & 23 & 0.147 & 35.97 & 8.78 & -2.232 & 0.367 \\
\hline Post & 23 & 0.456 & 38.36 & 7.44 & & \\
\hline Note: $\mathrm{p}<0.05$.
\end{tabular}

According to the achievement test pre-test results, the mean of the control group was 35.97 and the standard deviation was 8.78 ; the posttest mean is 38.36 and its standard deviation is 7.44 . The fact that the averages are very close to each other shows that the level of the group is close to each other according to the pre-test and post-test results. Since it was seen that there was no significant difference according to the results of the normality test, it was accepted that the data showed a normal distribution, as a result, the significance of the difference between the group averages was tested through the paired-sample t-test from parametric tests. The $\mathrm{p}$-value $(\mathrm{p}=.367)$ obtained as a result of the dependent group t-test analysis within-group pre-test post-test scores reveals that there is no significant difference between the means of the groups. This finding coincides with the teachers' views in the part of the findings regarding the first sub-question of the study. Participating teachers stated that they find themselves inadequate in overcoming reading difficulties and they need training on this subject. The fact that there was no difference between the pre-test and post-test scores of the untrained control group supports these findings as well.

\subsection{Results Regarding the Fourth Sub-question}

Testing the significant difference between the post-test scores of the experimental group and the control group regarding the Teacher Education Program, which was developed to overcome reading difficulties in students with dyslexia, is the fourth sub-question of the study, and the findings related to this purpose are included under this heading. The achievement test developed within the scope of the research was applied as a post-test to the control group, who continued traditional in-service training activities and did not receive the dyslexia teacher training program. While the training program was applied to the experimental group, the control group continued with traditional in-service training activities. After the program implementation, the post-test results were compared in order to compare the post-test results of both the experimental group and the control group and to evaluate the effectiveness of the program between the groups in which the program was applied and not applied.

Table-7. Findings regarding experimental group and control group post-test scores.

\begin{tabular}{c|c|c|c|c|c}
\hline Group & $\mathbf{N}$ & $\mathbf{S}-\mathbf{W}$ & $\overline{\mathbf{x}}$ & $\mathbf{S S}$ & $\mathbf{P}$ \\
\hline Experimental & 23 & 0.171 & 75.32 & 10.90 & 0.000 \\
\hline Control & 23 & 0.456 & 38.36 & 7.44 & \\
\hline Note: $\mathrm{p}<0.05$. &
\end{tabular}

According to the achievement test post-test results, the average of the experimental group was 75.32 and the standard deviation was 10.90; the average of the control group is 38.36 and its standard deviation is 7.44. The fact that the averages are quite far from each other shows that the levels of the two groups are different from each other. As it was seen that there was no significant difference according to the results of the normality test, it was accepted that the data showed a normal distribution, as a result, the significance of the difference between the group averages was tested through independent group t-test of from parametric tests. The p-value $(p=.000)$ obtained as a result of the independent group t-test analysis between the two groups reveals a significant difference between the means of the groups. As a result of the analysis, it can be said that the training program applied was quite effective in overcoming reading difficulties compared to traditional in-service activities according to both group averages and $\mathrm{p}<0.05$ significance level.

\subsection{Results Regarding the Fifth Sub-Question}

Findings related to the results of the statistically significant difference between the pre-test post-test scores of the teacher education program developed for the elimination of reading difficulties in students with dyslexia constitute the fifth sub-question of the study. Findings regarding this sub-purpose are given under this title.

The achievement test developed within the scope of the research was applied as a pre-test and a post-test to the experimental group who did not continue with traditional in-service training activities and joined the dyslexia teacher training program. While the training program was applied to the experimental group, the control group 
continued with traditional in-service training activities. After the program implementation, the experimental group pre-test and post-test results were compared in order to evaluate the effectiveness of the dyslexia teacher training program within the group.

Table-8. Findings regarding experimental group pre-test post-test scores.

\begin{tabular}{c|c|c|c|c|c|c|c}
\hline Test & $\mathbf{N}$ & $\mathbf{S}-\mathbf{W}$ & $\mathbf{x}$ & $\mathbf{S S}$ & $\mathbf{t}$ & $\mathbf{P}$ & $\mathbf{r}$ \\
\hline Pre & 23 & 0.803 & 35.54 & 10.36 & 29.642 & 0.000 & 0.88 \\
\hline Post & 23 & 0.171 & 75.32 & 10.90 & & & \\
\hline Note: $\mathrm{p}<0.05$.
\end{tabular}

According to the achievement test pre-test results, the average of the experimental group was 35.54 and the standard deviation was 10.36; the post-test mean is 75.32 and its standard deviation is 10.90 . The fact that the averages are quite far from each other shows that the level of the group is far from each other according to the pretest and post-test results. Since it was seen that there was no significant difference according to the results of the normality test, it was accepted that the data showed normal distribution, as a result, the significance of the difference between the group averages was tested through the dependent group t-test from parametric tests. The $\mathrm{p}$-value $(\mathrm{p}=.000)$ obtained as a result of the dependent group t-test analysis between the pre-test post-test scores of the groups reveals a significant difference between the means of the groups. The significant difference between the pre-test and post-test scores of the experimental group in favor of the post-test results and also the large difference between the average scores can be accepted as a clear indicator that the applied program is quite effective. During the research process, it was found that the dyslexia training program developed based on needs analysis, expert opinion and the relevant literature is extremely successful and effective, as a result of examining table 8 , which shows the results of the pre-test post-test analysis scores. According to the analysis results, the effect size of the program $(\mathrm{r}=.88)$ was found, and this value reveals that it is a big effect.

\subsection{Results Regarding the Sixth Sub-Questions}

The achievement test developed within the scope of the research was applied as a retention test to the experimental group in which the dyslexia teacher training program was applied, two weeks after the application. After the program implementation, the results of the experimental group post-test and the retention test were compared in order to evaluate the permanence of the effectiveness of the dyslexia teacher training program within the group.

Table-9. Findings regarding experimental group posttest and retention test scores.

\begin{tabular}{c|c|c|c|c|c|c}
\hline Test & $\mathbf{N}$ & $\mathbf{S - W}$ & $\overline{\mathbf{x}}$ & $\mathbf{S S}$ & $\mathbf{t}$ & $\mathbf{P}$ \\
\hline Post & 23 & 0.079 & 75.32 & 10.90 & 1.213 & 0.238 \\
\hline Retention & 23 & 0.171 & 72.06 & 10.57 & & \\
\hline Note: $\mathrm{p}<0.05$.
\end{tabular}

According to the retention test results, the average of the experimental group was 72.06 and the standard deviation was 10.57; the post-test mean is 75.32 and its standard deviation is 10.90. It shows that the averages are close to each other and the level of the group is close to each other according to the posttest and retention test results. Since it was seen that there was no significant difference according to the results of the normality test, it was accepted that the data showed normal distribution, as a result, the significance of the difference between the group averages was tested through the dependent group t-test from parametric tests. The $\mathrm{p}$-value $(\mathrm{p}=.238)$ obtained as a result of the dependent group t-test analysis within the group post-test and retention test scores reveals that there is no statistically significant difference between the means of the groups. The fact that there is no significant difference between the experimental group post-test and retention test scores, and also the small difference between the mean scores and standard deviations can be considered as a clear indicator that the effect of the applied program is permanent. In the research process, the finding that the dyslexia training program developed based on needs analysis, expert opinion, and the relevant literature is extremely successful, effective, and permanent is seen in table 9, which shows the results of the post-test and retention test scores.

\section{Discussion}

Considering that an estimated $5-10 \%$ of the world population has dyslexia, it is essential for teachers to properly understand what dyslexia is and how it affects their students. An article examining the results of a largescale survey of teachers in England and Wales $(\mathrm{N} \approx 2,600)$ shows that teachers have a basic understanding of the behavioral problems associated with dyslexia. The teachers lacked knowledge of the biological (ie neurological) and cognitive (ie processing) aspects of dyslexia. What's more, some teachers mentioned visual factors in their dyslexia definitions, although there is inconclusive evidence suggesting a direct relationship between visual function and dyslexia. Other findings show the importance of good quality teacher education in increasing teachers' confidence in working with dyslexia while increasing their knowledge of the cognitive aspects of dyslexia (Knight, 2018). While it is not the teacher's job to diagnose dyslexia, they need to understand the underlying behavioral and cognitive difficulties associated with dyslexia properly to identify those at risk and to intervene appropriately. Research into ways to improve symptoms associated with dyslexia has shown a positive effect of interventions on the person with dyslexia. It is known that interventions that prioritize phonological skills are effective in teaching reading to children with dyslexia. Phonological processing skills refer to the skills required to use phonemes (ie sounds in a language) to process speech and written language (Rose, 2009). The broad category of phonological processing includes the cognitive skills of phonological awareness (the ability to focus on and change sounds in spoken words) and phonological working memory retrieval (the ability to store and remember the correct phonemic sound from memory).

Some studies have reported a more holistic understanding of dyslexia in the teaching profession. For example, Regan and Woods (2000) conducted focus groups with 36 teachers and learning support assistants in the UK and 
asked them to define dyslexia. Focus group participants touched all areas by providing biological and cognitive descriptions to explain behavioral symptoms. However, the researchers noted that the understanding between individuals is different (Regan \& Woods, 2000). Another study surveyed 171 preservice teachers in the United States and the United Kingdom to investigate their misconceptions about dyslexia. They found that teachers in both countries reported some misconceptions about dyslexia. Most importantly, most of the pre-service teachers who participated in the questionnaire stated that dyslexia is caused by problems with visual perception. This is particularly relevant to the concept of "visual stress" in which a person can see a page differently due to print distortions on a white background. It has been reported that visual stress causes reading fatigue (Walliman, 2010)).

In order to measure knowledge and attitudes related to dyslexia, a survey for classroom teachers was developed in Turkey and within the scope of the survey, it was administered to 345 classroom teachers. Within the scope of the study, the knowledge levels of classroom teachers about dyslexia, dyspraxia, dyscalculia, and special learning difficulties were examined and it was concluded that almost all of the classroom teachers had insufficient knowledge on these issues. In their responses to open and closed-ended items, it was observed that they could not adequately define the relevant concepts (Şahin, Guven, \& Alatl, 2020). Within the scope of the research conducted by Altuntas (2010) the knowledge of classroom teachers about dyslexia was measured and interviews were conducted to determine what they did for students with dyslexia. As a result of the interviews, classroom teachers were asked to indicate the problems they see in their students. The common views of the teachers in different areas of reading difficulty were determined. These are very slow reading, illegible writing, distraction, late learning to read, confusing the letters "b" and "d", skipping letters, words, or lines, not being able to read the word they see right away, and confusing similar words to each other. According to the data obtained on classroom teachers' inclass practices for students with dyslexia, classroom teachers do not conduct a special study for their students. It was concluded that classroom teachers found themselves inadequate in the education of students with dyslexia. Besides, classroom teachers find themselves inadequate in the education of their students with dyslexia. Teachers stated that they need the training to overcome reading difficulties and do not know what kind of education should be given to students with dyslexia (Altuntas, 2010).

Teacher self-sufficiency beliefs can be defined as the assessment of teachers' perceived competencies and their ability to perform in the classroom to be effective in encouraging and encouraging desired student behavior and learning. Teacher self-sufficiency is not a uniform construct but differs according to contexts, groups, and cultures, it is argued that it should be studied concerning specific contexts, aspects and tasks because high self-sufficiency in one field does not mean high efficiency in another. For this reason, teachers who seem to have low self-sufficiency in conducting inclusive teaching practices show high self-sufficiency in other areas of their professional activities. Besides, teacher self-sufficiency in a particular area of professional performance is dynamic and can fluctuate throughout an individual's career. It has been shown that teachers' self-sufficiency beliefs regarding the implementation of inclusive teaching practices both affect teachers' attitudes towards inclusion and actual teaching behaviors to meet the changing educational needs of students in heterogeneous classes. Teachers' competencies in inclusive teaching competencies are powerful in that they can determine teachers' level of effort, commitment to teaching, and insistence on applying coping strategies when faced with a slowdown, trouble, or failure. These competencies can also affect teachers' ability to create supportive, inclusive classroom environments and teaching behaviors. High self-sufficiency in the application of inclusive teaching strategies encourages teachers' openness to new ideas and readiness to try new techniques. Teachers with high self-sufficiency tend to show more understanding, patience, and self-confidence when working with students with dyslexia.

Results from the studies show that teachers' knowledge of dyslexia is not consistent and is mainly based on behavioral descriptions. Moreover, teachers seem to have possible misunderstandings about dyslexia. Within the scope of this study, all of the participating teachers stated that they found themselves insufficient in dyslexia and needed training. Teachers reported that they had insufficient knowledge and understanding of reading difficulties and that they were either not trained or only given limited training to include individuals with dyslexia and special needs during their education. More importantly, research findings support the necessity of increasing the effectiveness of vocational education in the acquisition, development, and consolidation of teacher knowledge. Teachers express their need, desire, and readiness to receive such training as part of institutional teacher preparation programs or during continuing education and professional development. Teachers who know about self-sufficiency and dyslexia tend to apply inclusive teaching practices more successfully and effectively in their classroom, with more positive attitudes and less anxiety. However, it should be emphasized that to successfully use inclusive teaching practices, classroom teachers must have a range of skills and relevant knowledge that are not part of teacher education programs. Teachers who lack these skills may face difficulties when working with their students with dyslexia, and such negative experiences can reduce their self-sufficiency and inclusion attitudes. Negative attitudes and low inclusive competence among teachers can pose serious obstacles to inclusion. Research studies report the existence of a positive relationship between teachers' attitudes towards inclusion and their selfsufficiency beliefs about applying inclusive practices in the classroom. Increasing teachers' inclusive effectiveness and competencies are crucial to the fact that teachers' self-sufficiency beliefs about their abilities are stronger than they actually know or can achieve. Therefore, it seems important to increase the proficiency of classroom teachers regarding the reading difficulties experienced by their learners with dyslexia. As a result, teachers who consider themselves competent and receive the necessary training will both support their students with dyslexia more comprehensively and display a more positive attitude.

\section{Conclusion}

In this study, the effectiveness of the teacher training program, which was developed to help teachers who work with students with dyslexia gain skills to cope with reading difficulties, was examined and the results of the research are given below.

1) All teachers participating in the study find themselves incompetent in coping with reading difficulties.

2) In dealing with reading difficulties, most of the teachers who participated in the study did not receive detailed training in undergraduate education and in-service training on reading difficulties and they need training on this subject. 
3) Teachers' knowledge of dyslexia is insufficient and mainly based on behavioral descriptions, and teachers have inaccurate knowledge about dyslexia.

4) Teachers have problems in coping with reading difficulties in developing or using a common and standardized practice and activity.

5) The Teacher Training Program, which was developed to help teachers who work with students with dyslexia gain the ability to cope with reading difficulties, made a statistically significant difference between the experimental group that was applied and the control group that continued traditional in-service activities.

6) The Teacher Education Program, which was developed to help teachers who work with students with dyslexia gain the ability to cope with reading difficulties, created a statistically significant difference between the pre-test post-test scores of the experimental group applied.

7) The Teacher Education Program, which was developed to provide teachers who work with students with dyslexia with the ability to cope with reading difficulties, gave effective results in dealing with phonological awareness, word awareness, syllable awareness, rhyme awareness, and sentence awareness difficulties in the experimental group.

8) The Teacher Education Program, which was developed to help teachers who work with students with dyslexia gain the ability to cope with reading difficulties, yielded effective results in the experimental group that was applied in coping with fluent reading and reading comprehension difficulties.

9) The Teacher Education Program, which was developed to provide teachers who work with students with dyslexia with the ability to cope with reading difficulties, gave effective results in the design and implementation of teaching activities in coping with reading difficulties in the experimental group.

\section{Implications}

1) Courses related to students with dyslexia or reading difficulties and their education can be included in the undergraduate curriculum of classroom teaching departments.

2) In-service training and seminars on dealing with reading difficulties can be organized for classroom teachers.

3) Within the scope of the research, the Teacher Education Program, which was developed to provide teachers working with students with dyslexia the ability to cope with reading difficulties, can be applied to families by making the necessary adaptations and evaluating its effectiveness.

\section{References}

Altuntas, F. (2010). Classroom teachers? Knowledge about dyslexia and their trainings for dyslectic students. Published Master's Thesis. Ankara: Hacettepe University.

Brown, S., \& Melamed, L. (2012). Experimental design and analysis. California: Sage Publications.

Cohen, L., Manion, L., \& Morrison, K. (2017). Research methods in education. London: Routledge.

Creswell, J. W. (2007). Research design: Qualitative, quantitative, and mixed method approaches. California: Sage Publications.

Gliner, J. A., Morgan, G. A., \& Harmon, R. J. (2003). Pretest-posttest comparison group designs: Analysis and interpretation. Journal of the American Academy of Child and Adolescent Psychiatry, 42(4), 500-503.

Gwernan-Jones, R., \& Burden, R. L. (2010). Are they just lazy? Student teachers' attitudes about dyslexia. Dyslexia, 16(1), 66-86.

Hartas, D. (2010). Educational research and inquiry: Qualitative and quantitative approaches. London: Continuum International Publishing.

Hultquist, A. M. (2006). An introduction to dyslexia for parents and professionals. London: Jessica Kingsley Publishers.

Knight, C. (2018). What is dyslexia? An exploration of the relationship between teachers' understandings of dyslexia and their training experiences. Dyslexia, 24(3), 207-219. Available at: https://doi.org/10.1002/dys.1593.

Kubiszyn, T., \& Borich, G. (2003). Educational testing and measurement. New York: Jhon Wiley \& Son.

MEB. (2014). Child developed and educated learning difficulties. Ankara: Ministry of Education.

Moeckli, J. (2011). The qualitative interview. In Social Research: Theory, methods, and techniques (pp. 264-286): SAGE Publications, Ltd.

Regan, T., \& Woods, K. (2000). Teachers' understandings of dyslexia: Implications for educational psychology practice. Educational Psychology in Practice, 16(3), 333-347. Available at: https://doi.org/10.1080/713666081.

Reid, G. (2009). Dyslexia: A practitioner's handbook (4th ed.). New York: John Wiley \& Sons, Ltd.

Rose, S. J. (2009). Identifying and teaching children and young people with Dyslexia and literacy difficulties. Nottingham: DCFS Publications.

Şahin, R., Guven, S., \& Alatl, B. (2020). Investigation of the knowledge and attitudes of primary school teachers towards Dyslexia. Turkish Studies, 15(4), 2355-2372. Available at: http://dx.doi.org/10.47423/TurkishStudies.42099.

Sari, H. (2004). An analysis of burnout and job satisfaction among Turkish special school headteachers and teachers, and the factors effecting their burnout and job satisfaction. Educational Studies, 30(3), 291-306. Available at: https://doi.org/10.1080/0305569042000224233.

Sari, H. (2007). The influence of an in-service teacher training (INSET) programme on attitudes towards inclusion by regular classroom teachers who teach deaf students in primary schools in Turkey. Deafness \& Education International, 9(3), 131-146. Available at: https://doi.org/10.1179/146431507790559996.

Swerdlik, M. E., Edward, D., Sturman, P., \& Cohen, R. J. (2012). Psychological testing and assessment: An introduction to tests and measurement. Boston: McGraw-Hill Education.

Walliman, N. (2010). Research methods: The basics. London: Routledge.

Wendler, C. L., \& Walker, M. E. (2011). Practical issues in designing and maintaining multiple test forms for large-scale programs: In Handbook of Test Development. London: Routledge. 